\section{Commentary: Aortic valve reconstruction and the Ozaki procedure in children-Finding the best fit}

\author{
Subhadra Shashidharan, MD, and Paul Chai, MD
}

Aortic valve disease continues to be a challenging problem in pediatric patients. We continuously search for new innovations, as our best options are imperfect. In this issue of the Journal, Wiggins and colleagues ${ }^{1}$ from Great Ormond Street present their short-term results using the Ozaki procedure (neotricuspidization) and other valve reconstruction techniques in children and young adults. This is currently the largest retrospective single-center review in children and young adults, comprising 58 patients from 2015 to 2019. The median age at the time of surgery was 14.8 years. The smallest annular dimension in the cohort was $18 \mathrm{~mm}$. There was 1 late death unrelated to valve repair and 7 reoperations during a median follow-up of 14.1 months. The authors concluded that aortic leaflet repair provided acceptable short-term outcomes.

Initial enthusiasm for the Ozaki procedure may be understandable, given our current lack of dependable solutions for children with aortic valve disease. However, we should not ignore history and should keep in mind that short-term success has never been the issue with aortic valve repair. In this study, $25 \%$ of patients had greater than moderate aortic regurgitation at 3 years and $12 \%$ required reoperation within the short follow-up period. ${ }^{1}$ The durability of repair remains the question.

The role of aortic valve repair techniques including the Ozaki procedure remains to be defined. In some studies, including that from the host institution, patients undergoing the Ross procedure with similar dimensions as the current

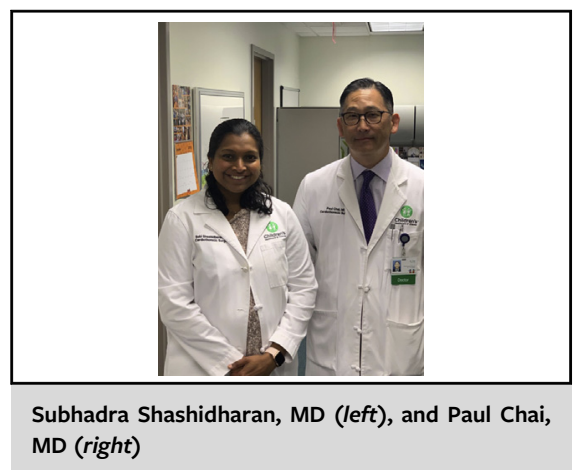

CENTRAL MESSAGE

Aortic valve repair can have

acceptable short-term results.

Effective patient selection will

yield optimal results.

cohort had a 10-year freedom from aortic valve reoperation of $80 \%$ to $92 \%, 2,3$ and thus it may be difficult to recommend aortic valve repair when the Ross procedure can have excellent outcomes. However, as the authors admit, aortic valve repair is not intended as a long-term solution. They propose several circumstances when aortic valve repair can be highly beneficial, such as in patients with anatomy unsuitable for the Ross procedure (eg, those with truncal arteriosus) or in staging patients toward aortic valve replacement with a prosthesis large enough to account for growth to adulthood. Another such situation may include patients at increased risk for root dilation, who could be staged toward a "reinforced" Ross procedure within an adult-sized gel-weave graft.

The challenge remains to find the best options for the care of aortic valve disease in children and young adults. The role of valve repair remains to be defined, but it appears that selective application in a particular group of patients may yield the best results.

From the Department of Surgery, Children's Healthcare of Atlanta, Emory School of Medicine, Atlanta, Ga.

Disclosures: Authors have nothing to disclose with regard to commercial support.

Received for publication Oct 30, 2019; revisions received Oct 30, 2019; accepted for publication Oct 30, 2019; available ahead of print Dec 18, 2019.

Address for reprints: Paul Chai, MD, Children's Healthcare of Atlanta, Emory School of Medicine, 1405 Clifton Rd NE, Atlanta, GA 30322 (E-mail: Paul.chai@choa. org).

J Thorac Cardiovasc Surg 2020;159:2380 $0022-5223 / \$ 36.00$

Copyright $₫ 2019$ Published by Elsevier Inc. on behalf of The American Association for Thoracic Surgery

https://doi.org/10.1016/j.jtcvs.2019.10.203

\title{
References
}

1. Wiggins LM, Mimic B, Issitt R, Ilic S, Bonello B, Marek J, et al. The utility of aortic valve leaflet reconstruction techniques in children and young adults. J Thorac Cardiovasc Surg. 2020;159:2369-78.

2. Elkins RC, Thompson DM, Lane MM, Elkins CC, Peyton MD. Ross operation: 16-year experience. J Thorac Cardiovasc Surg. 2008;136:623-30.

3. Tran PK, Tsang VY, Cornejo PR, Torii R, Dominguez T, Tran-Lundmark K. Midterm results of the Ross procedure in children: an appraisal of the subannular implantation with interrupted sutures technique. Eur J Cardiothorac Surg. 2017; 52:798-804. 